\title{
Feasibility of a Readiness Exam for Predicting Radiography Program Success: A Pilot Study
}

\author{
Tammy L. Webster \\ University of Nebraska Medical Center, tammy.webster@unmc.edu \\ Sarah B. McBrien \\ University of Nebraska Medical Center, sarah.mcbrien@unmc.edu \\ Gregory M. Mehrer \\ Sanford, greg.mehrer@gmail.com \\ Harlan R. Sayles \\ University of Nebraska Medical Center, hsayles@unmc.edu
}

Follow this and additional works at: https://nsuworks.nova.edu/ijahsp

Part of the Academic Advising Commons, Anatomy Commons, Curriculum and Instruction Commons, Higher Education Administration Commons, Other Medicine and Health Sciences Commons, and the Radiology Commons

This Manuscript has supplementary content. View the full record on NSUWorks here: https://nsuworks.nova.edu/ijahsp/vol18/iss2/10

\section{Recommended Citation}

Webster TL, McBrien SB, Mehrer GM, Sayles HR. Feasibility of a Readiness Exam for Predicting Radiography Program Success: A Pilot Study. The Internet Journal of Allied Health Sciences and Practice. 2020 Jan 01;18(2), Article 10.

This Manuscript is brought to you for free and open access by the College of Health Care Sciences at NSUWorks. It has been accepted for inclusion in Internet Journal of Allied Health Sciences and Practice by an authorized editor of NSUWorks. For more information, please contact nsuworks@nova.edu. 


\title{
Feasibility of a Readiness Exam for Predicting Radiography Program Success: A Pilot Study
}

\begin{abstract}
ABSTRACT

Background: Research investigating predictors of academic success in rigorous health science education is valuable for curricular intervention for identified at-risk students. Various predictors of success have been investigated, but the literature is insufficient when examining anatomy and physiology readiness scores as they correlate to radiography curricular success. This pilot study assessed the correlation between readiness exam scores and programmatic course GPA to determine if the scores could be used as a metric for identifying academic success resources for incoming students. Cohorts of the radiography program at a midwestern health sciences center demonstrated a longitudinal trend of difficulty with anatomy and physiology programmatic coursework. Therefore, researchers set out to investigate whether or not readiness exam scores, in addition to the metrics they were already utilizing, could be used as a tool for early academic remediation. Objective: The objective of this study was to determine if the anatomy and physiology readiness exam scores would be reliable indicators of programmatic success in anatomy and physiology program coursework. Design: This investigation occurred in two phases: a retrospective correlational phase and a quasi-experimental phase. Methods: Retrospective data from cohorts that matriculated between 2013 and 2017 ( $n=91)$ was collected and de-identified. Data included prerequisite grade point average (GPA) and grades from anatomy and physiology course taken during the program. During the quasi-experimental phase, a sample of students $(n=18)$ completed a readiness examination. The scores from this examination were correlated with prerequisite GPA and program anatomy and physiology GPA. Results: Data analysis revealed prerequisite GPA and the anatomy and physiology section of the readiness examination to be strong and moderate predictors of programmatic anatomy and physiology course grades, respectively. Conclusion: Predictors of curricular success in a radiography program's anatomy and physiology coursework are essential factors to consider in relation to admissions practices, curricular prerequisite standards, and on-boarding of new students, especially those identified as at-risk.
\end{abstract}

\section{Author Bio(s)}

Tammy Webster, PhD, MPA, RT(R)(M), is an Associate Professor in the College of Allied Health Professions at the University of Nebraska Medical Center in Omaha, NE. She also serves as the Director for the Radiography, Cardiovascular Interventional Technology, and Computed Tomography Programs.

Sarah McBrien, PhD, is an Assistant Professor in the College of Allied Health Professions at the University of Nebraska Medical Center in Omaha, NE. She also serves as the Director of Curriculum and Learning Assessment for the college.

Gregory Mehrer, MBA, RT(R)(CT) is a practicing Radiographer, CT Technologist, and educator at Sanford Health in Sioux Falls, SD.

Harlan Sayles, MS, is a statistician with the Department of Biostatistics in the College of Public Health at the University of Nebraska Medical Center in Omaha, NE. 


\title{
TIAHSP \\ The Internet Joutnal of Allied Health Sciences and Practice
}

Dedicated to allied health professional practice and education

Vol. 18 No. 2 ISSN 1540-580X

\section{Feasibility of a Readiness Exam for Predicting Radiography Program Success: A Pilot Study}

\author{
Tammy Webster \\ Sarah B. McBrien \\ Gregory M. Mehrer \\ Harlan R. Sayles \\ University of Nebraska \\ United States
}

\begin{abstract}
Background: Research investigating predictors of academic success in rigorous health science education is valuable for curricular intervention for identified at-risk students. Various predictors of success have been investigated, but the literature is insufficient when examining anatomy and physiology readiness scores as they correlate to radiography curricular success. This pilot study assessed the correlation between readiness exam scores and programmatic course GPA to determine if the scores could be used as a metric for identifying academic success resources for incoming students. Cohorts of the radiography program at a midwestern health sciences center demonstrated a longitudinal trend of difficulty with anatomy and physiology programmatic coursework. Therefore, researchers set out to investigate whether or not readiness exam scores, in addition to the metrics they were already utilizing, could be used as a tool for early academic remediation. Objective: The objective of this study was to determine if the anatomy and physiology readiness exam scores would be reliable indicators of programmatic success in anatomy and physiology program coursework. Design: This investigation occurred in two phases: a retrospective correlational phase and a quasiexperimental phase. Methods: Retrospective data from cohorts that matriculated between 2013 and 2017 ( $n=91$ ) was collected and de-identified. Data included prerequisite grade point average (GPA) and grades from anatomy and physiology course taken during the program. During the quasi-experimental phase, a sample of students $(n=18)$ completed a readiness examination. The scores from this examination were correlated with prerequisite GPA and program anatomy and physiology GPA. Results: Data analysis revealed prerequisite GPA and the anatomy and physiology section of the readiness examination to be strong and moderate predictors of programmatic anatomy and physiology course grades, respectively. Conclusion: Predictors of curricular success in a radiography program's anatomy and physiology coursework are essential factors to consider in relation to admissions practices, curricular prerequisite standards, and on-boarding of new students, especially those identified as at-risk.
\end{abstract}

Keywords: predictor, radiography, readiness exam

(c) The Internet Journal of Allied Health Sciences and Practice, 2020 


\section{INTRODUCTION}

As the demands for the healthcare workforce continue to evolve with advances in imaging technology, more pressure is placed on radiography programs to educate and prepare students for entry-level practice in an environment of constant change. The expectations for the knowledge base, clinical application, and critical thinking of entry-level radiologic technologists are expanding as a result. The knowledge and skills learned in the professional academic setting aim to prepare future radiologic technologists for the American Registry of Radiologic Technologists (ARRT) national certification exam. Graduating from a quality radiography program and successfully passing the ARRT exam enables the radiologic technologist to be a patient advocate through adherence to imaging safety practices, proper operation of ionizing radiation, and effective clinical judgement. As a result of these substantial expectations and responsibilities of the radiologic technologist, academic programs need to consider variables that may determine student readiness and success in a rigorous professional curriculum.

Thus, this pilot study assessed the following variables: prerequisite grade point average (GPA), anatomy and physiology programmatic course grades, and anatomy and physiology readiness exam scores for radiography students at a midwestern health sciences center from 2013-2017. In partnership with Exam Master, a readiness exam was tailored to the needs of radiography students in order to assess subject matter knowledge in four areas: anatomy and physiology, algebra, general chemistry, and statistics. While the exam assessed multiple content areas, anatomy and physiology scores were the focus of our investigation, as this content area directly aligns with the radiography curriculum.

Historically, the program under study utilized the prerequisite GPA as a key predictor of programmatic success. The purpose of this study was to examine if the anatomy and physiology component score of the readiness exam was a more reliable predictor of curriculum success in the anatomy and physiology coursework than the previously used prerequisite GPA.

Studies investigating predictors of success in professional curricula would be valuable for admissions practices and deliberate academic interventions targeting at-risk students. While predictors of success in academic healthcare programs have been explored, the majority of the research was not focused on radiography as a professional discipline. The existing literature provides the foundation for additional research that will be relevant to radiography curricula.

\section{LITERATURE REVIEW}

Like many healthcare professions, success on a national certification examination is a valuable metric for radiography programs. Students, faculty, future employers, and patients are all invested in the graduate's ability to pass the exam on the first attempt. Educational programs under Joint Review Committee on Education in Radiologic Technology (JRCERT) programmatic accreditation are required to publicly report ARRT outcomes on program websites. ${ }^{1}$ This public reporting allows prospective applicants to compare outcome data across competing programs.

While institutions are interested in achieving strong passing rates, the implications for failing the ARRT exam are most significant for students. Costs associated with becoming a radiologic technologist can be sizable. The cost of tuition, living expenses, state licensure fees where applicable, and the fees associated with the credentialing application add up. Despite successfully graduating from a radiography program, many states require graduates to pass a registry exam before practicing in the field. The 2018 ARRT outcomes show 11,571 candidates took the exam. The mean score was $83.6 \%$, and $89.4 \%$ passed the exam. ${ }^{2}$ Applicants are permitted three attempts in three years to pass the certification exam at a cost of roughly $\$ 200$ per application submission. If the applicant fails after three attempts, two routes are available to regain eligibility: enrollment in the same or different educational program in the discipline or enrollment in a program under the advanced placement option, which is offered at the discretion of the institution's program director. ${ }^{3}$

\section{Curriculum Preparation for the ARRT}

To avoid matriculating students to a radiography program who are ill-suited for the field and unlikely to pass the ARRT, programs may be interested in identifying predictors of success in a professional curriculum because their success in the curriculum is a predictor of how well the student will perform on the national certification exam.

The American Society of Radiologic Technologists (ASRT) provides a curriculum guide for programs in imaging science. The goal of the curriculum guide is to outline a common body of knowledge that is essential for, in this case, an entry-level radiologic technologist. ${ }^{4}$ The professional guide states that "general education is an integral part of the development of a professional radiographer."4 The general education knowledge provides a framework to enhance content and application of the radiography curriculum. Strictly a guide, the ASRT radiography curriculum guide suggests that general education cover the following subject areas: mathematics and reasoning, communication, humanities, information systems, social sciences, and natural sciences. ${ }^{4}$

(C) The Internet Journal of Allied Health Sciences and Practice, 2020 
With the ARRT's additional requirement of an associate degree or higher to apply for the certification exam in radiography in 2015 , ASRT eliminated the need for specific general education requirements; instead, each program has the prerogative to determine the extent to which prerequisites are required and in what content areas. Depending upon the program's degree award, there may be varying published lists of prerequisite coursework to enter a radiography program. ${ }^{4}$

\section{Predictors of Curriculum Success}

Existing literature shows that programs have used predictors such as entrance exams and prerequisite course grade point averages to estimate the probability of success in the professional curriculum. ${ }^{5-8}$ Studies have indicated these predictors may serve to identify academic concerns early in a professional program and be utilized to aid students at risk of not being successful. ${ }^{9-11}$

Abbott et al (2008) found a statistically significant association between a pre-assessment score and the nursing certification exam results. Moreover, the study showed that admitting GPA of students who passed the nursing certification exam was higher than those who failed. The nursing college in the research study reviewed GPAs before matriculation and continued to monitor them for academic difficulties so that early intervention could be initiated. ${ }^{5}$

Abele et al (2013) supported the idea of "scholastic aptitude" as a key predictor in nursing students' success with the finding that science course performance could be used as a predictor for success in the program. Scholastic aptitude was measured based upon the incoming student's pre-nursing GPA and an entrance exam conducted at the beginning of the professional program. ${ }^{6}$

Newton and Moore (2009) offered a related finding. Scores on a standardized entrance exam taken at the beginning and end of a nursing program found that scholastic aptitude demonstrated early in the nursing program was predictive of student readiness to be successful on the certification examination. ${ }^{9}$

Vealé et al (2017) authored a study related to radiologic sciences suggesting that the Health Education Systems, Inc. (HESI) radiography exit examination had a positive correlation with the ARRT registry examination. ${ }^{12}$ In this study, the researchers examined the relationship between the HESI Admission Assessment and specific admission criteria in an effort to reveal associations between the HESI exam and the ARRT first attempt exam scores. Findings suggested no correlation between the HESI Admission Assessment and program admission criteria except in situations where a minimum passing score of 70 was applied to the Admission Assessment, which omitted some students. With the exception of one student in each of the two cohorts, those students who would have been eliminated by the HESI also left the program, failed the ARRT exam, or yielded low grades, defined as Cs or Ds, on a consistent basis in the professional curriculum. Results of the study imply that the HESI Admission Assessment is a favorable supplementary tool to use for admission criteria when an appropriate minimum passing score is set and may ultimately guide the selection of students who will be successful in the curriculum. ${ }^{12}$ Because of the small sample size, the researchers indicated data from replicated studies would be valuable to further support the findings.

Other than the study listed above, there has been little research conducted on entrance or readiness exam results as a predictor of curriculum or registry success in the field of imaging sciences. Consequently, this pilot study presents a valuable opportunity to advance the field of imaging science through data-supported results. Correlations between incoming student's prerequisite coursework GPAs, anatomy and physiology scores on the readiness examination, and program coursework grades in anatomy and physiology were examined to identify relationships between these variables that might enhance the program's ability to predict success in the professional program.

A readiness exam is a test designed to measure the developmental factors involved in the learning process. The aim is to discover if a learner is in a position to benefit from a particular course of instruction. ${ }^{13}$ The readiness exam, typically multiple choice in format, is designed to measure core competencies.

Health professions are finding it is important to use a preliminary diagnostic exam to predict students' potential performance. ${ }^{14}$ The results of this study will guide radiography educational programs in determining the feasibility of predicting programmatic success as well as provide a tool for early identification of at-risk students, which for the purpose of this study is defined as a student who is likely to require intervention based on failure to maintain a minimum course GPA of 1.67.

(C) The Internet Journal of Allied Health Sciences and Practice, 2020 


\section{METHODS}

To meet the ASRT Curriculum Guide for general education, the radiography program at a midwestern health sciences center has published a list of prerequisite coursework for applicants to complete prior to matriculation. The prerequisite list is found in Table 1 below.

Table 1. Prerequisite List

\begin{tabular}{lc}
\hline SUBJECT AREA & $\begin{array}{c}\text { CREDIT HOURS } \\
\text { REQUIRED }\end{array}$ \\
\hline ENGLISH COMPOSITION & 6 \\
COLLEGE ALGEBRA & 3 \\
STATISTICS & 3 \\
HUMANITIES & 6 \\
MEDICAL TERMINOLOGY & 2 \\
SPEECH/ORAL COMMUNICATION & 3 \\
COLLEGE CHEMISTRY & 4 \\
PHYSICS & 4 \\
ANATOMY AND/OR PHYSIOLOGY & 4 \\
ELECTIVES & 15 \\
\hline TOTAL & 50 \\
\hline
\end{tabular}

For years, performance in these prerequisite courses served as the primary predictor of curriculum success. The program faculty (and investigators in this study) set out to determine if a more reliable metric, such as a readiness examination, could predict success in program coursework and serve to identify students who may be at risk for academic difficulty. Specifically, the researchers aimed to determine if the anatomy and physiology component score was a more reliable predictor of curriculum success than the previously used prerequisite GPA. Investigators focused on students' performance in the anatomy and physiology courses that are taken during the first year of the two-year program. This study was classified as exempt by the Institutional Review Board.

\section{Study Design}

The readiness examination was created by a third-party company, Exam Master, whose primary focus is board preparation for medical professions. A team of subject matter experts (SMEs) developed content component areas related to core prerequisite coursework common to various medical professions. The SMEs wrote test questions and conducted peer reviews to confirm question accuracy and difficulty level. A test form was created and field tested to ascertain item discrimination and quality. Item response theory and Rasch analysis were performed to identify individual test item reliability and validity. Post-test reviews were also collected from test-takers, and revisions were made accordingly. Activities related to the development and validation of the test items were conducted by Exam Master without input from faculty at our institution.

Component areas were pre-selected by the research investigators to align with prerequisite coursework for matriculation into the professional radiography program. The examination consisted of 100 multiple-choice questions broken down into four component areas: anatomy and physiology (50\%), general chemistry (30\%), algebra (10\%), and statistics (10\%).

\section{Subjects \& Setting}

Grade point averages from students who began the radiography program from 2013 to 2017 ( $n=91$ ) were collected and analyzed to examine the correlation between prerequisite GPA and programmatic anatomy and physiology (A\&P) course scores while in the professional program.

A convenience sample of 18 first-year radiography students participated in this quasi-experimental research study by completing the readiness examination in the first week of coursework, having had less than ten hours of direct instruction in the professional curriculum. Investigators then evaluated associations among prerequisite coursework GPA, radiography program A\&P GPA, and the A\&P component score on the readiness exam. Participants were students enrolled in a university-based baccalaureate radiography program.

The study was described to students during the consent process, indicating: participation in taking the readiness exam was voluntary; data would be anonymous and aggregate; exam administration was limited to 90 minutes; results of the readiness exam would not be factored into course grades; there would be no financial burden on the students for participation; and their score on the readiness exam would have no impact on their relationship with program faculty. A faculty member not directly associated with 
the program administered the readiness examination to students. Students were given two hours of clinical vacation time for participating in this research.

The collaborating radiography program operates three separate campuses in three different cities. All testing took place synchronously in classrooms at each campus location. Students were instructed to bring a computer to access the exam. The readiness exam was delivered via the World Wide Web and did not include a secured browser. Pencil and scratch paper were provided.

\section{Data Management}

Prerequisite GPA and program A\&P GPA were collected and verified from our admissions office to be combined into a master Excel spreadsheet that contained prerequisite GPA, program A\&P course grades and GPA, overall readiness exam score, and A\&P component exam score. Table 2 itemizes the grading scale used to determine prerequisite and program A\&P GPAs.

Table 2. Grading Scale

\begin{tabular}{lcc}
\hline LETTER GRADE & PERCENT SCORE & $\begin{array}{c}\text { GRADE POINTS } \\
\text { (4 POINT SCALE) }\end{array}$ \\
\hline $\mathrm{A}^{+}$ & $97-100$ & 4.00 \\
$\mathrm{~A}$ & $93-96.99$ & 4.00 \\
$\mathrm{~A}-$ & $90-92.99$ & 3.67 \\
$\mathrm{~B}+$ & $87-89.99$ & 3.33 \\
$\mathrm{~B}$ & $83-86.99$ & 3.00 \\
$\mathrm{~B}-$ & $80-82.99$ & 2.67 \\
$\mathrm{C}+$ & $77-79.99$ & 2.33 \\
$\mathrm{C}$ & $73-76.99$ & 2.00 \\
$\mathrm{C}-$ & $70-72.99$ & 1.67 \\
$\mathrm{D}+$ & $67-69.99$ & 1.33 \\
$\mathrm{D}$ & $63-66.99$ & 1.00 \\
$\mathrm{D}-$ & $60-62.99$ & .67 \\
$\mathrm{~F}$ & $0-59.99$ & 0 \\
\hline
\end{tabular}

\section{Statistical Analysis}

The distribution of prerequisite GPAs for the students who completed the readiness exam $(n=18)$ and those who did not $(n=73)$ were examined using the Mann-Whitney $U$ test to determine that the groups' GPAs did not differ statistically. The Mann-Whitney $U$, a nonparametric test, was used because the distribution of GPAs was not normal.

A set of simple linear regressions was performed to correlate $A \& P G P A$ for coursework taken during the first year of the radiography program (PROG A\&P GPA) with prerequisite GPA (PREREQ GPA), total exam score (EXAM TOTAL), and A\&P component exam score (EXAM A\&P) to examine relationships between each of the variables. All analyses were conducted using Statistical Package for Social Sciences (SPSS) version 25.15

\section{RESULTS}

\section{Descriptive Statistics}

The mean and standard deviations for each GPA for students enrolled in the radiography program over five years is shown in Table 3 along with the mean and standard deviations for each GPA for the 18 students who completed the readiness exam.

Table 3. Descriptive Statistics

\begin{tabular}{lccc}
\hline & $\mathrm{N}$ & $\begin{array}{c}\text { PREREQ GPA } \\
\text { MEAN, STANDARD DEVIATION }\end{array}$ & $\begin{array}{c}\text { PROG A\&P GPA } \\
\text { MEAN, STANDARD DEVIATION }\end{array}$ \\
\hline NOT EXAMINED & 73 & $3.57, .26$ & $3.17, .54$ \\
EXAMINEES & 18 & $3.59, .24$ & $3.21, .60$ \\
ALL STUDENTS 2013- & 91 & $3.59, .26$ & $3.18, .55$ \\
2017 & & & \\
\hline
\end{tabular}

(C) The Internet Journal of Allied Health Sciences and Practice, 2020 
The GPAs of the 18 students who participated in the readiness examination were not statistically different than that of the 73 students who did not, (PREREQ GPA $p=.909$, PROG A\&P GPA $p=.780$ ).

Two variables were predictors of program GPA in anatomy and physiology coursework. Anatomy and physiology component scores (EXAM A\&P) were a significant predictor of program GPA in anatomy and physiology coursework (PROG A\&P GPA) at the $\mathrm{a}=0.05$ level with a correlation coefficient of $.479\left(\mathrm{R}^{2}=.230\right)$. Prerequisite GPA (PREREQ GPA) was a significant predictor of program GPA in anatomy and physiology coursework (PROG A\&P GPA) at the $\alpha=0.01$ level with a correlation coefficient of .338 $\left(\mathrm{R}^{2}=.114\right)$.

Scores on the anatomy and physiology component of the examination (PROG A\&P GPA) were also correlated with prerequisite GPA at .553 ( $\left.\mathrm{R}^{2}=.306\right)$, significant at the $\mathrm{a}=0.05$ level. Results from correlational studies are shown below in Table 4.

Table 4. Pearson Correlations

\begin{tabular}{lccc} 
& PROG A\&P GPA & PREREQ GPA & EXAM TOTAL \\
\hline PREREQ GPA A & $.338(p=.001)$ & & \\
EXAM TOTAL ${ }^{B}$ & $.430(p=.075)$ & $.567(p=.014)$ & $.874(p<.001)$ \\
EXAM A\&P B & $.479(p=.045)$ & $.553(p=.017)$ & \\
\hline
\end{tabular}

${ }^{a}$ Correlations calculated for all 91 students. ${ }^{b}$ Correlations calculated for 18 students who completed readiness exam.

\section{DISCUSSION}

Because many academic programs are interested in identifying metrics by which they can better assess applicant readiness for their program and/or better identify matriculants who may be at risk for academic difficulties, results from this study are promising. The moderate and significant relationship between prerequisite GPA and program GPA in anatomy and physiology coursework affirms that this metric is a useful tool for predicting success in the radiography program. Adding an additional tool such as the readiness examination may augment decisions that were previously based solely on performance in prerequisite coursework. The items that assessed A\&P concepts (50) did produce scores that were statistically significant predictors of program A\&P GPA. Therefore, the other 50 items meant to assess chemistry, algebra, and statistics could be removed from the examination without compromising score meaning for program directors.

Considering student scores on the 50 A\&P items on the readiness examination alongside prerequisite GPA may be the most reliable method for predicting student success in A\&P coursework during a radiography program. Shortening the examination by 50 items significantly decreases the amount of time students and faculty or staff must devote to the examination itself, and prerequisite GPA data is typically readily available through an institution's admission process. In the absence of resources to implement such an examination, the prerequisite GPA may suffice as a predictor of A\&P course success.

The aim of the study was not to identify a threshold GPA that may help identify at-risk students. Instead, multiple factors should be taken into consideration by each institution before determining whether additional support services should be offered to a group of students based on their incoming GPA. Factors to consider might include timing and pace at which anatomy and physiology instruction is delivered, services such as tutoring and review sessions offered by anatomy and physiology departmental faculty, and online resources available through the program or library.

\section{Additional Insight}

The strong correlation that exists between the A\&P component exam score and performance in A\&P coursework may provide early validity evidence for the 50 items included in the readiness examination that focused on anatomy and physiology principles. Based on this study, that validity evidence should only be extended to radiography students in similar programs with similar requirements for entry into the program.

\section{Limitations}

Generalization of the results across all radiography programs should be weighed cautiously. However, with the curriculum guide provided by the American Society of Radiologist Technologists, curricular comparisons are possible. The convenience sample used in this study was limited to students who were selected as part of the admissions process, which naturally limits the sample to students who met minimum qualifications for entry to the program. Nevertheless, the results from this study add to the body of research examining factors contributing to programmatic success and early identification of at-risk students for radiography programs. 
The longitudinal investigation of the relationship between prerequisite GPA and programmatic course grades in anatomy and physiology helps to demonstrate the association between performance in prerequisite coursework and program coursework over a number of years as trends in curriculum and assessment change, environmental and contextual factors affect the culture in which students learn, and influence from accrediting bodies impacts decision-making.

An additional limitation is the variation found in the prerequisite coursework of incoming students. Though a published list of prerequisite courses is followed, applicants satisfy the requirements via several different pathways and may have completed coursework beyond the list of prerequisites or have life experiences that better prepare them directly for success in a radiography program (or any professional health sciences program, for that matter).

\section{FUTURE DIRECTIONS}

Opportunities to advance the findings of this research include collaborating with peer programs to increase sample size, investigating readiness exam scores as a predictor of curriculum success in other imaging modality programs such as radiation therapy and magnetic resonance imaging, and utilizing a different readiness exam than the one used in this study.

\section{RECOMMENDATIONS}

Based upon the findings of this study, it is suggested that when selecting a readiness exam for the purpose of predicting student success in a curriculum, select an exam developer that offers content filtering options, such as testing for A\&P content, so that the examination can be tailored to the program's needs rather than assessing general science knowledge. Doing so may decrease the amount of time students and personnel are required to be present for the exam administration, as in our case.

\section{CONCLUSION}

The goal of this investigation was to determine if supplementing current onboarding processes with the addition of a readiness examination was necessary and feasible. Two major conclusions can be drawn. First, the readiness examination, as it was delivered to incoming radiography students, did provide some additional information about students' knowledge in the areas of anatomy and physiology that may have been helpful during a selection process and/or in identifying at-risk students. Second, while the readiness exam did provide additional insight, the prerequisite GPA may continue to be an equally effective predictor of success. Institutions that carefully consider the time and resources required to deliver such an assessment, the legal implications of integrating such an assessment as part of the selection or onboarding process, and other metrics available to program faculty are provided with an opportunity to identify at-risk students. This identification then prompts the allocation of resources aimed to optimize student success.

\section{REFERENCES}

1. Joint Review Committee on Education in Radiologic Technology. 2014 Accreditation Standards. https://www.jrcert.org. Updated 2019. Accessed August 12, 2019.

2. American Registry of Radiologic Technologists. National Comparison Report. https://www.arrt.org/partners/schoolseducators/educator-resources. Updated 2018. Accessed April 3, 2019.

3. American Registry of Radiologic Technologists. Earn ARRT Credentials. https://www.arrt.org/earn-arrtcredentials/requirements/examination-requirement/after-the-exam/three-attempts-in-three-years. Updated 2018. Accessed April 3, 2019.

4. American Society of Radiologic Technologists. Radiography Curriculum. https://www.asrt.org/docs/defaultsource/educators/curriculum/radiography/acad_curr_radcurrfinal2017_20170206.pdf?sfv rsn=2. Updated 2017. Accessed on April 3, 2019.

5. Abbott AA, Schwartz MM, Hercinger M, Miller CL, Foyt ME. Predictors of success on national council licensure examination for registered nurses for accelerated baccalaureate nursing graduates. Nurse Educator. 2008;33(1): 5-6.

6. Abele C, Penprase B, Ternes R. A closer look at academic probation and attrition: What courses are predictive of nursing student success? Nurse Education Today. 2013;33(3):258-261. 
7. Carroll AM, Schuster GM. Correlation between students' dental admission test scores and performance on a dental school's competency exam. Journal of Dental Education. 2015;79(11):1325-1329.

8. Schauner S, Hardinger KL, Graham MR, Garavalia L. Admission variables predictive of academic struggle in a PharmD program. American Journal of Pharmaceutical Education. 2013;77(1):8.

9. Newton SE, Moore G. Use of aptitude to understand Bachelor of Science in Nursing student attrition and readiness for the national council licensure examination-registered nurse. Journal of Professional Nursing. 2009;25(5):273-278.

10. Newton SE, Smith LH, Moore G, Magnan M. Predicting early academic achievement in a baccalaureate nursing program. Journal of Professional Nursing. 2006;23(3):144-149.

11. Uyehara J, Magnussen L, Itano J, Zhang S. (2007). Facilitating program and NCLEX-RN success in a generic BSN program. Nursing Forum. 2007;42(1):31-38.

12. Vealé BL, Clark KR, Killion JB, Sharma P. The HESI admission assessment and radiography exit examination as predictors for student success. Journal of Medical Imaging and Radiation Sciences. 2017;48(1): 90-94.

13. Readiness Test. https://www.encyclopedia.com/medicine/encyclopedias-almanacs-transcripts-and-maps/readinesstest. Updated 2001. Accessed April 3, 2019.

14. Simon EB, McGinniss SP, Krauss BJ. Predictor variables for NCLEX-RN readiness exam performance. Nursing Education Perspectives. 2013; 34(1):18-24.

15. International Business Machines. SPSS statistics. 2017. 